\title{
Organizational Intervention at an Aquarium
}

\section{Vargas-Hernandez $\mathrm{JG}^{1 *}$ and Salazar $\mathrm{NL}^{2}$}

${ }^{1}$ University Center for Economic and Managerial Sciences, University of Guadalajara, Periferico Norte, Nucleo Universitario Los Belenes, Zapopan, Jalisco, Mexico ${ }^{2} \mathrm{PhD}$ in Management Sciences, Christopher Columbus University, Campus Calasanz, Veracruz-Medellin highway, Col. Puente Moreno, Boca del Rio, Ver, Mexico

\begin{abstract}
The objective of this research is to identify the labor perceptions of the guides on their teamwork, job knowledge, leadership and Motivation as there is the assumption that some of these dimensions may explain why the visitors have a poor perception of their work. Through a descriptive study with an experimental cross-sectional study design, the questionnaire technique, developed to measure these dimensions is used. The results indicate that workers have full knowledge of the job but lack integration and Motivation. The type of intervention proposed is the program Guides on Development specifically designed to improve the effectiveness of the group.
\end{abstract}

Keywords: Job knowledge; Leadership; Motivation and Teamwork

\section{Summary}

The objetive of this research is to identify job perceptions of guides on their teamwork, knowledge of the job, leadership and motivation because there is an assumption that some of these dimensions may explain why visitors have a poor perception of their work. Through a descriptive study with an experimental cross-sectional study design, the questionnaire technique, developed to measure such dimensions is used. The results indicate that the guides have full knowledge of the job but lack integration and Motivation. The type of intervention proposed is the program Developing guides designed to improve the effectiveness of the group.

\section{Introduction}

The quality of working life in Mexico is a topic of discussion between the theoretical and the practical. What becomes real and what stays in fantasy is because in the business world of this country social responsibility is a term coined more to meet the requirements of buyers and investors to fulfill the commitment to society to be sustainable. According to the OECD [1], Mexico is below average in all welfare indicators of quality of life, except two: subjective satisfaction and civic engagement, including employment and remuneration are included, education and skills, work-life balance and sense of community.

Therefore, it is expected the same dysfunctionality of this macroenvironment at micro level. In this regard, the company policy is studied: the Aquarium is to seek the satisfaction of the needs of its visitors through its functions and values of quality, respect, honesty and teamwork; and maintain a continuous improvement tool. However on the data collected from mailbox complaints are precisely the guides, who have direct dealings with all visitors, those identified by their lack of commitment to time to bring this satisfaction to the user experience.

The purpose of this paper is to identify the perceptions of guides through the evaluation of four key dimensions for their work: teamwork, job knowledge, leadership and Motivation. Thus, in the next section the background to the problem, all of which were provided by key company personnel who have access to information on their performance and the complaint box are addressed; then the current problems based on the guiding question that gave rise to this research Is there any factor that may explain the perception of the performance of the guides developed?

Then this paper justifies the reason why this work is relevant in that department and conducts a brief review of the theory of specifying service quality indicators relevant to the dimensions studied. After, it is explained the research method used to collect data and results are reported for later to describe the intervention plan "Developing Guides" which aims to improve the effectiveness of group of workers report. At the end of the observed phenomenon recommendations are integrated.

Notably a heartfelt gratitude is due to top managers and officials besides 30 respondents who kindly took the time to answer surveys.

\section{Background of the Problem}

The Aquarium is a civil association dedicated to the maintenance and display of aquatic species both freshwater and saltwater, as well as the preservation of the environment. Currently has 18 galleries made up of about 250 species. The organization is divided into two areas: the technical area and the administrative area. The first is responsible for the functional part of the aquarium facilities, health of each of the organisms that are exhibited there and conservation of ecosystems; while the second is responsible of human capital, administrative and visitors.

The Department of User Services belongs to the administrative area and is headed by two deputy chiefs. A total of 30 guides work in both shifts. The function of this department is to serve all visitors entering the aquarium facilities in the public area.

The profile for hiring guides is temporary in nature with little or almost no possibility of promotion. It is designed for young students from 18 to 23 years of age, which provide a service of 6 hours daily, with only one day off a week. The work schedule includes only two shifts: the morning from 8 to 14:00 p.m. and evening from 14:00 to 20:00 p.m., although the position has the flexibility to adjust the 42 hours weekly working according to their study schedule each guide to support to

*Corresponding author: Vargas-Hernandez JG, University Center for Economic and Managerial Sciences, University of Guadalajara, Periferico Norte, Nucleo Universitario Los Belenes, Zapopan, Jalisco, Mexico, Tel: 523337703340 Extn: 256585; E-mail: jvargas2006@gmail.com, jgvh0811@yahoo.com, josevargas@cucea.udg.mx

Received April 04, 2016; Accepted May 17, 2016; Published May 27, 2016

Citation: Vargas-Hernandez JG, Salazar NL (2016) Organizational Intervention at an Aquarium. Bus Eco J 7: 210. doi:10.4172/2151-6219.1000210

Copyright: (c) 2016 Vargas-Hernandez JG, et al. This is an open-access article distributed under the terms of the Creative Commons Attribution License, which permits unrestricted use, distribution, and reproduction in any medium, provided the original author and source are credited. 
continue with their studies. The monthly salary is around $\$ 3,200.00$ pesos and food stamps are added.

According to recent interviews with the Department of Education, responsible for receiving the information contained in the complaint box, evidence of the dissatisfaction of visitors regarding the performance of the guides is found in galleries. The revised information expressed discontent of users about their treatment, specifically attention. Also, key personnel had the opportunity to comment on the lack of commitment of workers who currently make up the department and apathy for their work, combined with the constant bickering between them.

Given the above, it is of great interest to know why the guides are perceived in this way, as research on job satisfaction conducted last December showed as results that $100 \%$ of the guides were satisfied with their work, leading to the need to investigate whether the instrument was properly designed and implemented correctly. On the other hand, it could also be an indicator of the lack of trust that owns this body of workers to express their views freely.

\section{Delimitation of the Problem}

The guide's performance has deteriorated noticeably, so that visitors although they do not stop going, do not take a good image of the care and customer service they receive. The shop keepers Care Users are aware that the quality of care has been detrimental to the passing of generations of guides and attribute such behavior to the education received at home and to the changing society attached to the electronic media. The guides for their part, say that the bosses are not too strict with the lazy companions and do not care about monitor that the rules are met among their peers. They also perceive that the boss is completely disinterested in the performance of the department.

For all the above, the following question emerges: What are the perceptions of the guides regarding the dimensions of teamwork, job knowledge, leadership and Motivation?

\section{Justification}

This work is important because it is an assessment tool of perceptions whose results will provide a clear picture of where lies the area of improvement in the department User Support, which detection and correction will increase the quality of service by improving the performance of the guides and thus not only reflect organizational health at the departmental level but also organizational generating the desired customer satisfaction.

The latter is the main goal because without visitors, the aquarium could not exist and not exist, the impact within the company affect all workers and the species that are housed there; while externally, produce impact in the following sectors: environment by eliminating funding for research projects; labor statewide unemployment and the tourism sector in both state and national levels.

\section{Theoretical and Conceptual Framework}

According Gutierrez [2], the main ideas about the theory of quality service began to take shape between the 80 's and 90's. Edward Deming is credited with the concept of total quality. This worked at Western Electric Hawthorne (W. E.) plant and created management theory proposing organizations humanist ideas through its 14 principles. Among which include point 1 and 9 that hint at service improvement and the elimination of barriers to teamwork, respectively.
Joseph Juran is considered the father of quality. He also worked on the W.E. and in his work he emphasized the administration responsible for meeting the needs of customers. He developed the trilogy quality of Juran consisting of planning, quality control and quality improvement. Kaoru Ishikiwa, a more contemporary theorist whose work helped to simplify statistical methods for quality control, expresses the philosophy that organizations must put quality on all decisions made by management, which will not see the light if the management shelve it.

It is also important to mention the consultant Philip Crosby, as it noted that subject to the quality problems, these were related to the Motivation and expectations of workers. Armand Feigenbaun first coined the term total quality control and quality distinguishes the term as a way of corporate life while total quality control is an effective system aimed at customer needs activities. Finally, Senge [3] is also a representative of the quality for its theoretical contribution of learning organizations and it aims to cultivate five disciplines, which build a shared vision and team learning which are part of the purposes of this research into the body of guides.

Therefore, the concept of the quality service in which the research is based, i.e., the performance of the guides, returns qualities of all the items mentioned by previous authors as it seeks to strengthen teamwork, the leadership, Motivation and knowledge of the position, dimensions that are present in the desired product quality as the result. Thus, service quality management managers and team members who want to learn to work efficiently, taking into account the expectations of the employee and customer needs.

\section{Research Method}

For knowing the labor perception presented in the guides department User Support Aquarium, an explanatory study is conducted with an experimental and cross-sectional study design, which was applied during the last week of January 2016 (Monday 25 to Sunday of the month 31). The total guides throughout the department correspond to 30 , including 15 in the morning shift and 15 in the evening shift.

The inclusion criteria for the sample were as follows:

A. Guidelines on permanent contracts.

B. Guides belonging to User Support department.

So it was sampled at 30 guides, who met those requirements. Being an explanatory study and an experimental methodological design of cross section, it is designed an instrument based on the values expressed in the policy of the company and the information gathered with key personnel is designed, giving as results four dimensions of job perception: job knowledge (knowledge), leadership (leadership), Motivation (Motivation) and teamwork (team). These dimensions are measured through the 37 items contained in the questionnaire with values from 1 to 5 on the Likert scale, with the number 1 the highest appreciation and lower number 5 . The following table shows questions with the dimension evaluated (Table 1).

IBM SPSS version 19 software was used to validate the reliability through Cronbach's alpha coefficient which explains that the closer is to 1 , the greater its reliability to determine the reliability of the instrument. In this research shows 0.863 (grouped) and a .870 (individual) which indicates that, according to Hair, Anderson, Tatham and Black, is respectable. Table 2 shows these results are observed.

\section{Analysis of Results}

The lowest scores in the dimensions of the questionnaire reveal 


\begin{tabular}{|c|c|c|}
\hline Code & Dimensions & Items \\
\hline Knowledge & Job knowledge & $2,3,9,13,15,16,17,20,21,28,32,33,36$ \\
\hline Teamwork & Teamwork & $4,7,11,23,24,26,35,37$ \\
\hline Leadership & Leadership & $6,10,14,19,25,31,34$ \\
\hline Motivation & Motivation & $1,5,8,12,18,22,27,29,30$ \\
\hline \multicolumn{2}{|c|}{ Source: Own elaboration } \\
\hline
\end{tabular}

Table 1: Dimensions of work perception.

\begin{tabular}{|l|c|c|c|}
\hline Team, Motivation, Leadership, Knowledge & Individual & Grouped \\
\hline Number of cases & 30 & 0.870 & 0.863 \\
\hline$\%$ & & $100 \%$ & $100 \%$ \\
\hline Cases excluded & & 0 & 0 \\
\hline$\%$ & & $0.0 \%$ & $0.0 \%$ \\
\hline Total items & 37 ítems & 4 items \\
\hline Source: Own elaboration & &
\end{tabular}

Table 2: Cronbach's alpha reliability.

to what area of improvement should focus intervention plan. Thus, the percentages reveal the leadership dimension $(75.4 \%)$ as the main point of interest, followed by motivation dimension (80.4\%), while the TEAM $(81 \%)$ dimension only exceeds the latter by almost $1 \%$. The closer dimension to $100 \%$ is the dimension of knowledge (91\%) but no for this reason can no longer improved.

Paying special attention to the gender aspect, it could also be found a similar relationship in the order of scores given to these dimensions, for example, in the case of leadership dimension again get the lowest score in both populations being of $67.14 \%$ for males and $80.95 \%$ for women while KNOWLEDGE dimension regains highest percentages with $89.23 \%$ for males and $92.82 \%$ in women. However, the second dimension with lower scores change in the perception of gender, with TEAM for a $71.25 \%$ males and Motivation in women with a $85.92 \%$

\section{Diagnostic}

Although its capabilities can enhance the Aquarium, guides have full knowledge of their post. However, there are certain demotivating factors such as organizational climate by a lack of labor integration that leads them to have a bad perception of the boss plus they feel their work is not recognized. This confirms the information provided by key personnel on the low morale of the members of the department. It is important to note at this point that questions about the leadership dimension they were focused to know if the staff felt the support of their leader, so the result indicates a need to encourage communication by superiors with their subordinates.

\section{Symptoms}

a) Lack of confidence in the top management. When the guides have adverse situations in galleries, they do not feel confident to approach their superiors asking for support; the same case happens when requesting permits as they have the belief that they will be rejected.

b) The example of leadership is not positioned. The guides do not consider the bosses as an example of behavior. Also the lowest scores were repeated in the item about the perception of decisions made by superiors, noting that few sometimes they agreed with them.

c) Failure to consider feedback. The guides are not communicated of their improvements and performance in galleries. d) Lack of Motivation to deal with visitors. In their responses is noted lethargy that produces them to deal with visitors denoted.

e) Lack of communication with fellows from the technical area. Guides not have the confidence to approach with their colleagues in the technical area to ask questions of visitors.

f) Lack of communication with others guides. Just as the preceding paragraph, it is needed to improve the climate of trust to coordinate work in galleries with their peers.

Planning: In this phase, it is explained how research is carried out through coordination with the company and the time devoted to each activity. Such coordination is determined at a meeting with the supervisors of both shifts. The scheme is based on the model of planned change proposed by Lippitt, Watson and Wesley, and in Table 3 we can see how the schedule is structured for weeks.

Implementation: According to the above results, an intervention plan aims to improve the effectiveness of teams with the program: Guidelines on Development, which is a project of human development based on the needs of Motivation of human factor of the Aquarium. This program is divided into three parts: Employee Recognition Program, Representative Participation Program and Performance Evaluation. Table 4 explains in detail the employee recognition program.

For the second part of the program Guides in Development: The Representative Participation Program is convened to carry out a consensus approach to the theory of three needs of David McClelland (1987) to satisfy the sense of affiliation and belonging to the company. The objective pursued is that the guides feel heard and appreciated as part of his department. In addition to that activity, it allows them to discard the bad impression they have on the selflessness of their superiors

The dynamic is that the 15 members of each shift (total 30) to choose two representatives for the last weekend of each month to meet Saturday or Sunday according to the attendance of four representatives and to talk about the concerns, suggestions, problems and recommendations from the guide with better performance per shift. Members of this program will include two guides in the morning shift and two in the evening shift and the deputy heads of each shift.

In these meetings are set specific goals to develop each month agreement, taking into consideration the working season in which they are (if low or high season) with respect to schedule changes and procedures. This in order to work in an organized and unified as a department, without dialing any differentiation in shifts regardless of the specific demands for each shift involving the use of facilities for visitors.

For example, for future holiday season of carnival times, the entry and exit will be modified for guides both to avoid risks to their persons and to resolve the situation of closure of access routes for the beginning and end of the shows. The specific goals of this month which included the two weeks that are held parades, will be five: Getting earliest check in time to avoid mishaps, inviting visitors to go more fluid through their routes in the galleries, be aware of any conduct or state drawback of a visitor in order to invite him to leave the premises, pay attention to the health of visitors to direct them to the Medical Service if one felt unwell and be communicated with the deputy heads in case of a problem both inside and outside the premises.

Evaluation: For the latter part of the program Guides in Development, Performance Evaluation will be made using a scale 


\begin{tabular}{|c|c|c|c|c|c|c|c|}
\hline Phases & $\begin{array}{c}\text { Week } 1 \\
\text { 25-31 Jan }\end{array}$ & $\begin{array}{l}\text { Week } 2 \\
1-7 \text { Feb }\end{array}$ & $\begin{array}{c}\text { Week } 3 \\
\text { 8-14 Feb }\end{array}$ & $\begin{array}{c}\text { Week } 4 \\
\text { 15-21 Feb }\end{array}$ & $\begin{array}{c}\text { Week } 5 \\
\text { 22-28 March }\end{array}$ & $\begin{array}{c}\text { Week } 6 \\
\text { 29-6 March }\end{array}$ & $\begin{array}{c}\text { Week } 7 \\
\text { 7-13 March }\end{array}$ \\
\hline Exploration & a & & & & & & \\
\hline Entry & 9 & & & & & & \\
\hline Diagnosis & & a & & & & & \\
\hline Planning & & $\pi$ & & & & & \\
\hline Action & & & a & a & a & & \\
\hline Evaluation & & & & & & a & \\
\hline Termination & & & & & & & a \\
\hline
\end{tabular}

Table 3: Schedule of activities.

\section{Steps to follow}

a) Conduct to be strengthened

b) Objective

c) Participants

d) Description

e) Improvement of indicators

f) Incentives

g) Logistics for recognition

Source: Adapted Guía ABE (2012).

\section{Description}

Attend all visitors who come to the Aquarium with enthusiasm and cordiality

Improve care guides towards a friendly and helpful service that allows user satisfaction.

30 guides User Support department.

Guides must attend punctually to work and to changes in the galleries; properly wear the uniform and provide a coherent and comprehensive explanation of the gallery where they are. In addition to monitoring the correct use of the facilities and the delivery and reception of audio equipment in galleries. Will have to meet the regulations and present a good attitude of service to users,

i.e., be cordial and take the initiative to approach and solve these doubts visiting the area.

\section{- Assistance.}

- Timeliness.

- Corporative image (Uniform, position, name tag).

- Service attitude.

- Responsibility.

-Compliance with the regulations.

- Speech.

For each turn will be selected a guide who has obtained the highest rating of the above indicators and will be acknowledged with group recognition of his/her shift and photograph will be posted on the bulletin boards. They also will receive double food stamps at the end of the month.

Two photos of the guides with the best performance by shift will be placed on the information board at door of workers and on the information board of the department itself, and its mention will be unveiled beginning of each month in the Fishbowl Barrier Reef with the deputy chief shift, a few minutes before opening the aquarium for the morning shift and a few minutes after the last visitor leaves the premises for the evening shift.

Table 4: Employee recognition program.

\begin{tabular}{|l|l|l|}
\hline $\mathbf{1 0}$ & $\leftarrow$ & Respect standards work area \\
\hline $\mathbf{9}$ & $\leftarrow$ & He/she has the initiative to approach users to answer questions \\
\hline $\mathbf{8}$ & $\leftarrow$ & Employs a studied speech of galleries \\
\hline $\mathbf{7}$ & $\leftarrow$ & Takes care of the image that gives to visitors \\
\hline $\mathbf{6}$ & $\leftarrow$ & Greet visitors warmly \\
\hline $\mathbf{5}$ & $\leftarrow$ & Delivers good audio material \\
\hline $\mathbf{4}$ & $\leftarrow$ & Speak into the microphone \\
\hline $\mathbf{3}$ & $\leftarrow$ & Make your changes in time in the galleries \\
\hline $\mathbf{2}$ & $\leftarrow$ & Arrive early. \\
\hline $\mathbf{1}$ & $\leftarrow$ & Assists every day to work. \\
\hline
\end{tabular}

Table 5: Performance Evaluation (BARS).

based to behavior measurement (BARS) because it facilitates obtaining more accurate ratings when selecting behaviors identified of the job $[4,5]$. The scale used for the department User Service is integrated in the following way as expressed in Table 5. By scale are obtained the performance levels of the guides at Aquarium adhered to the strategy of the company that it is to respond effectively and cordiality to visitors.

The ten behaviors distinguish positive attributes of behavior expected in each guide and arranged from lowest to highest, 1 being the most common expected behavior and up the scale to 10 where the ideal expected behavior noted. It is worth mentioning that only deputy heads will have access to this information and the ability to qualify the performance [6-9]. They will be responsible for applying the scale each one in his shift. Those guides with lower results will be fed back informally in galleries in order to support them to better perform their value and will be followed to foster a climate of trust and fraternity.

\section{Conclusions and Recommendations}

Today, although it is true that the survival of enterprises is due to 
the product or service offered, it is obvious the lack of integration of human capital within the main targets, as this capital translates into hidden costs to get lost in inadequate management of the human factor.

Human capital management requires more than a simple look of achievement and fulfillment of goals assigned to each person, which are certainly important as their impacts on the results of the company. Superficially it appears to be considered human capital to develop a thorough selection process of the future worker who will be integrated into the culture of the organization but in the course of its passage through the latter forgets employee satisfaction that, while not generate notable gains, results in productivity and effectiveness in the products or services offered to potential customers.

The Aquarium is interested in countering this wave of oversights and therefore, despite having a deviation within its values expressed in the policy of the company in relation to the performance of the guides, implements the project Guides Development to address the needs present within the User Support Department. Thus, it can get a reflection of the importance of maintaining good communication with workers as it is the only way to know their opinion, prospects and how they feel about the organization.

Because the objective of this work is to identify the perceptions of guides on four dimensions because visitors feel that exhibit poor performance, this research aims first to strengthen the field of Motivation and teamwork to further assess whether to consolidate these areas it makes possible to obtain improved performance.

Moreover, the results also suggest a second intervention to analyze where is located the dimension of leadership in greater depth so that the position of deputy heads and their performance is also recognized.

\section{References}

1. OECD (2013) Mexico. OECD Better Life Index.

2. Gutierrez HP (2010) Calidad total y productividad. (3rd edn), Mc Graw Hill: Mexico.

3. Sengue $P(2005)$ The Fifth Discipline. Buenos Aires, Argentina, Granica

4. Snell S, Bohlander G (2013) Administración de recursos humanos (16 ed). Quéretaro, QRO: CENGAGE learning.

5. ABE (2012) Bue association us employers recognition program, buenos employers Association.

6. Veracruz Aquarium (2015) Historia.

7. Hair J, Anderson R, Tatham R, Black W (2006) Multivariate data analysis. (6 $6^{\text {th }}$ edn) Spain: Pearson Prentice Hall.

8. Lippit R, Watson J, Wesley B (1980) The dynamics of planned change. Routledge Publishers: Argentina.

9. McClelland D (1987) Human motivation. New York: Cambridge University Press. 